\title{
Recurrent Submandibular Gland Carcinoma ex Pleomorphic Adenoma
}

National Cancer Institute

\section{Source}

National Cancer Institute. Recurrent Submandibular Gland Carcinoma ex Pleomorphic

Adenoma. NCI Thesaurus. Code C153808.

The reemergence of submandibular gland carcinoma ex pleomorphic adenoma after a period of remission. 